Provided for non-commercial research and education use. Not for reproduction, distribution or commercial use.

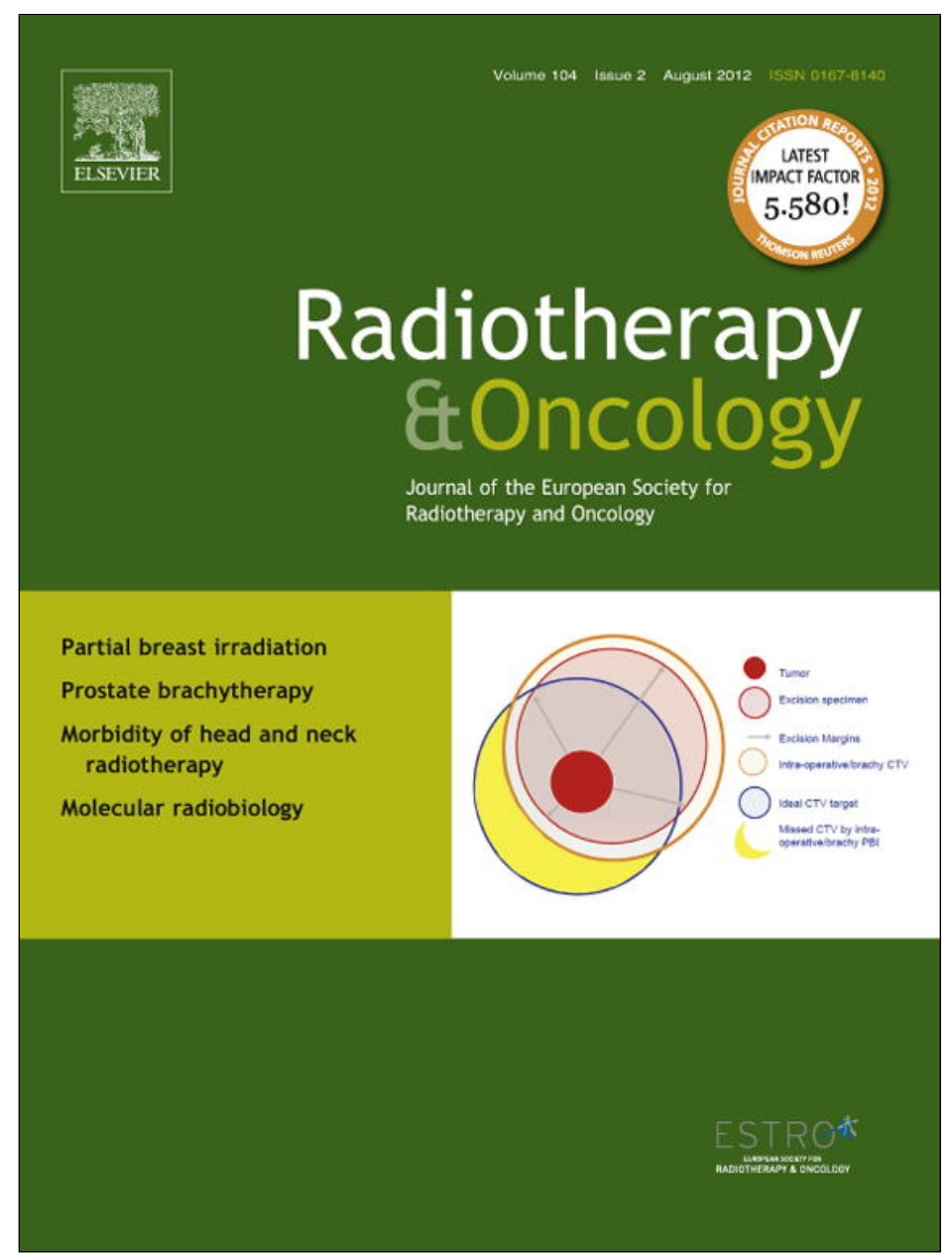

This article appeared in a journal published by Elsevier. The attached copy is furnished to the author for internal non-commercial research and education use, including for instruction at the authors institution and sharing with colleagues.

Other uses, including reproduction and distribution, or selling or licensing copies, or posting to personal, institutional or third party websites are prohibited.

In most cases authors are permitted to post their version of the article (e.g. in Word or Tex form) to their personal website or institutional repository. Authors requiring further information regarding Elsevier's archiving and manuscript policies are encouraged to visit:

http://www.elsevier.com/copyright 
Breast conserving therapy

\title{
The impact of dose heterogeneity on late normal tissue complication risk after hypofractionated whole breast radiotherapy
}

\author{
Yat Tsang $^{\mathrm{a}, *, 1}$, Joanne Haviland ${ }^{\mathrm{b}, 1}$, Karen Venables ${ }^{\mathrm{a}, 1}$, John Yarnold $^{\mathrm{c}, 1}$, \\ on behalf of the FAST Trial Management Group
}

${ }^{\mathrm{a}}$ Mount Vernon Cancer Centre, Middlesex; ${ }^{\mathrm{b}}$ Institute of Cancer Research Clinical Trials and Statistics Unit (ICR-CTSU); and ${ }^{\mathrm{c}}$ Institute of Cancer Research and the Royal Marsden Hospital, Sutton, UK

\section{A R T I C L E I N F O}

\section{Article history:}

Received 12 January 2012

Received in revised form 8 June 2012

Accepted 17 June 2012

Available online 16 July 2012

\section{Keywords:}

Treble trouble

Hypofractionation

Breast trials

\begin{abstract}
A B S T R A C T
Background and purpose: Linear quadratic models predict that hypofractionation increases the biological effect of physical dose inhomogeneity. The clinical significance of this effect was tested retrospectively in a trial of adjuvant breast hypofractionation.

Methods: The UK FAST trial randomised 915 women after breast conservation surgery between standard fractionation and two dose levels of a 5-fraction regimen delivering 5.7 or $6.0 \mathrm{~Gy}$ fractions in 5 weeks, using 3D dosimetry. Logistic regression tested for association between the absolute volumes receiving different isodose level $>100 \%$ of prescribed dose (hotspots) and the risk of change in 2-year photographic breast appearance. The strength of this association was compared between control and hypofractionated groups.

Results: Three hundred and ninety datasets from 11 participating centres were available for analysis. At 2 years post-randomisation, 81 (20.8\%) had mild change and 24 (6.2\%) had marked change in photographic breast appearance. After adjusting for breast size and surgical deficit, there was no statistically significant association between the risk of 2-year change in breast appearance and dose inhomogeneity in either the control or hypofractionated schedules, according to the various definitions of hotspots analysed. The magnitude of the effect of dosimetry on 2-year change in breast appearance did not vary significantly between control and hypofractionated schedules for any of the dosimetry parameters ( $p>0.05$ for all heterogeneity tests).

Conclusion: Dose inhomogeneity had no greater impact on the risk of 2-year change in photographic breast appearance after hypofractionated breast radiotherapy than after standard fractionation.

(C) 2012 Elsevier Ireland Ltd. All rights reserved. Radiotherapy and Oncology 104 (2012) 143-147
\end{abstract}

The routine use of hypofractionation in breast radiotherapy is supported by outcome data of four large randomised clinical trials in women with early breast cancer [1-7]. Residual concerns include the impact of dose inhomogeneity on the risk of adverse effects after hypofractionated schedules, so-called 'treble trouble' [8-10]. A causal association between breast dose inhomogeneity and the risk of late tissue complications is suggested by the 5 years follow up results of a UK randomised trial $(N=306)$ comparing $2 \mathrm{D}$ versus $3 \mathrm{D}$ breast dosimetry [11]. Assuming dose distribution matters, it is not known if residual dose inhomogeneity in patients treated using 3D dose compensation contributes to a higher risk of adverse effects after hypofractionated radiotherapy than after standard regimens. Against this background, a retrospective analysis of a UK hypofractionation trial, which recently published its 2 years

\footnotetext{
* Corresponding author. Address: Radiotherapy Physics, Mount Vernon Hospital, Northwood, Middlesex HA6 2RN, UK.

E-mail address: yatmantsang@nhs.net (Y. Tsang).

1 On behalf of the FAST Trial Management Group.
}

follow-up results [12], has been undertaken to test the hypothesis that residual dose inhomogeneity has a greater impact on late adverse effect in women prescribed hypofractionated whole breast radiotherapy, even when delivered in conformity with the International Commission on Radiation Units and Measurements (ICRU) $[13,14]$.

\section{Methods}

\section{FAST trial study population}

Between 2004 and 2007, 915 patients participated in the UK FAST trial, a prospective randomised clinical trial of adjuvant whole breast radiotherapy testing 5 once-weekly fractions of $6.0 \mathrm{~Gy}$ (test group 1, iso-effective with control if $\alpha / \beta=4 \mathrm{~Gy}$ ) and $5.7 \mathrm{~Gy}$ (test group 2, iso-effective with control if $\alpha / \beta=3 \mathrm{~Gy}$ ) against a control arm of 25 fractions of $2.0 \mathrm{~Gy}$ in terms of late normal tissue effects after local excision of early breast cancer [12]. The trial eligibility criteria included (i) age not younger than 50 years old, (ii) invasive 
carcinoma breast, (iii) pathological tumour size smaller than $3 \mathrm{~cm}$, (iv) complete microscopic resection with negative axillary node. The exclusion criteria were patients who required (i) mastectomy, (ii) lymphatic radiotherapy, (iii) radiotherapy breast boost and (iv) neoadjuvant or adjuvant cytotoxic therapy. Patients were randomised $(1: 1: 1)$ between the three trial arms.

\section{Definition and assessment of late adverse radiation effects in the FAST trial}

The primary endpoint of the FAST trial was late radiation-induced changes in breast appearance scored on a graded 3-point scale (none, mild or marked change) from serial photographs scored by three observers blind to treatment allocation [15] at 2 and 5 years post-radiotherapy compared to post-surgical baseline photographs. The START trial confirmed year 2 to be a valid time point for assessment, given a strong correlation between photographic scores at years 2 and 5 [1]. FAST trial recruitment was completed in March 2007, so 5-year assessments were unavailable for this analysis.

\section{Radiotherapy technique}

All patients were treated in a supine position with the help of immobilisation devices such as a breast board. The radiotherapy plan consisted of two standard tangential fields with non-divergent posterior field edges. The dose was prescribed to the standardised prescription point defined in the Standardisation of Breast Radiotherapy (START) Trial [16], half-way between the lung surface and the skin surface on the perpendicular bisector of the posterior treatment beam edge. The FAST protocol followed the ICRU reports 50 and 62 guidelines, recommending variation of dose throughout the treated volume to lie between $-5 \%$ to $+7 \%$ of prescribed dose. This was achieved using three dimensional (3D) dose compensation methods to ensure a maximum dose (Dmax) $<107 \%$ of the prescribed dose. By ICRU definitions, Dmax is the maximum dose received by a sphere volume with a diameter $>15 \mathrm{~mm}$. For this study, Dmax was defined as the maximum dose to a volume $>2 \mathrm{cc}$ $[13,14]$.

The majority of patients were treated with simple forward planned multi-leaf collimator (MLC) segment fields/Field in Field (FIF) technique and the rest of them were treated using physical breast compensators or inverse planned MLC segment fields.

\section{Dosimetry data collection and analysis}

The majority of commercial planning systems were capable of export either in RTOG or DICOMRT format. When exported in this way, data sent to the quality assurance (QA) team included planning computed tomography (CT) scans, treatment plan parameters, details of structures outlined and the radiation dose within the treatment volume computed by the planning system. Although the FAST trial protocol encouraged participating centres to use full CT planning, it was not a compulsory trial entry requirement. This study only used plans with a complete CT set in order to ensure accurate estimation of absolute breast volumes. As it was not a mandatory requirement to outline the breast, analysis was performed by exporting the whole dose cube of a patient's plan to obtain the whole patient volume's dose volume histogram (DVH). For conventional breast radiotherapy treatment utilising a tangential pair with non-divergent posterior beam edges, the cumulative treatment volumes receiving $50 \%$ of the prescribed dose were used to represent the whole breast treatment volume. The limitation of using this treatment volume surrogate is the inclusion of lung and heart volumes within the $50 \%$ isodose, although this effect should be minimised by the trial's recommendations of maximum lung distance and maximum heart distance in the treatment volume to be less than 2 and $1 \mathrm{~cm}$, respectively [17].

In order to investigate the dose heterogeneity effect on late tissue complications, this study used the cumulative breast volumes receiving more than the prescribed dose as the definitions of "hotspots". Absolute volumes of breast tissues exposed to $\geqslant 50 \%$, $\geqslant 100 \%, \geqslant 103 \%, \geqslant 105 \%$ and $\geqslant 107 \%$ of the prescribed dose were recorded.

\section{Statistical methods}

The absolute breast volumes receiving $\geqslant 100 \%, \geqslant 103 \%, \geqslant 105 \%$ and $\geqslant 107 \%$ of the prescribed dose were summarised using the medians and the inter-quartile ranges (IQRs). Medians were chosen instead of means as the distributions were highly skewed. As very few patients had marked change in breast appearance, the mild and marked change categories were combined to define the endpoint of any change in photographic breast appearance at 2 years versus none.

For each dose zone, medians were used to split the distribution into two groups for the analysis: <median and $\geqslant$ median. As

Table 1

Patient characteristics of this study sample $(n=390)$ compared with overall distribution in FAST Trial $(n=915)$.

\begin{tabular}{|c|c|c|}
\hline & $\begin{array}{l}\text { Distribution in study } \\
\text { sample, } n(\%)\end{array}$ & $\begin{array}{l}\text { Overall distribution in } \\
\text { FAST Trial (\%) }\end{array}$ \\
\hline \multicolumn{3}{|l|}{ Age (years) } \\
\hline $50-59$ & $138(35)$ & 36 \\
\hline $60-69$ & $184(47)$ & 48 \\
\hline $70-79$ & $61(16)$ & 14 \\
\hline $80-$ & $7(2)$ & 2 \\
\hline Mean (SD) [range] & $63.2(7.5)[50-88]$ & $62.9(7.2)[50-88]$ \\
\hline \multicolumn{3}{|c|}{ Time from surgery to randomisation (weeks) } \\
\hline $\begin{array}{l}\text { Median (interquartile } \\
\text { range) [range] }\end{array}$ & $5.4(4.1-6.7)[1.4-21.1]$ & $5.8(4.3-7.4)[0.4-22.1]$ \\
\hline \multicolumn{3}{|l|}{ Histological type } \\
\hline Ductal & $298(76)$ & 74 \\
\hline Lobular & $32(8)$ & 10 \\
\hline Other & $60(16)$ & 16 \\
\hline \multicolumn{3}{|l|}{ Axillary surgery } \\
\hline Sampling & $207(53)$ & 44 \\
\hline Clearance & $67(17)$ & 27 \\
\hline $\begin{array}{l}\mathrm{SNB}^{\mathrm{a}} \text { with or without } \\
\text { sampling }\end{array}$ & $102(26)$ & 25 \\
\hline Other & $14(4)$ & 4 \\
\hline \multicolumn{3}{|c|}{ Pathological tumour size $(\mathrm{cm})$} \\
\hline$<1$ & $121(31)$ & 28 \\
\hline $1-$ & $200(51)$ & 54 \\
\hline $2-$ & $69(18)$ & 18 \\
\hline Mean (SD) [range] & $1.3(0.6)[0.05-6.0]$ & $1.4(0.7)[0.05-11.4]$ \\
\hline \multicolumn{3}{|l|}{ Tumour grade } \\
\hline 1 & $138(35)$ & 34 \\
\hline 2 & $212(54)$ & 55 \\
\hline 3 & $38(10)$ & 11 \\
\hline Unknown & $2(1)$ & 0 \\
\hline \multicolumn{3}{|c|}{ Adjuvant systemic therapy } \\
\hline Yes & $345(88)$ & 88 \\
\hline No & $45(12)$ & 12 \\
\hline \multicolumn{3}{|l|}{ Breast size ${ }^{\mathrm{b}}$} \\
\hline Small & $210(54)$ & 57 \\
\hline Medium & $144(37)$ & 32 \\
\hline Large & $36(9)$ & 11 \\
\hline \multicolumn{3}{|l|}{ Surgical deficit ${ }^{\mathrm{b}}$} \\
\hline Small & $215(55)$ & 54 \\
\hline Medium & $111(29)$ & 27 \\
\hline Large & $64(16)$ & 20 \\
\hline
\end{tabular}

\footnotetext{
a $\mathrm{SNB}=$ sentinel node biopsy.
}

b Assessed from baseline photographs. 


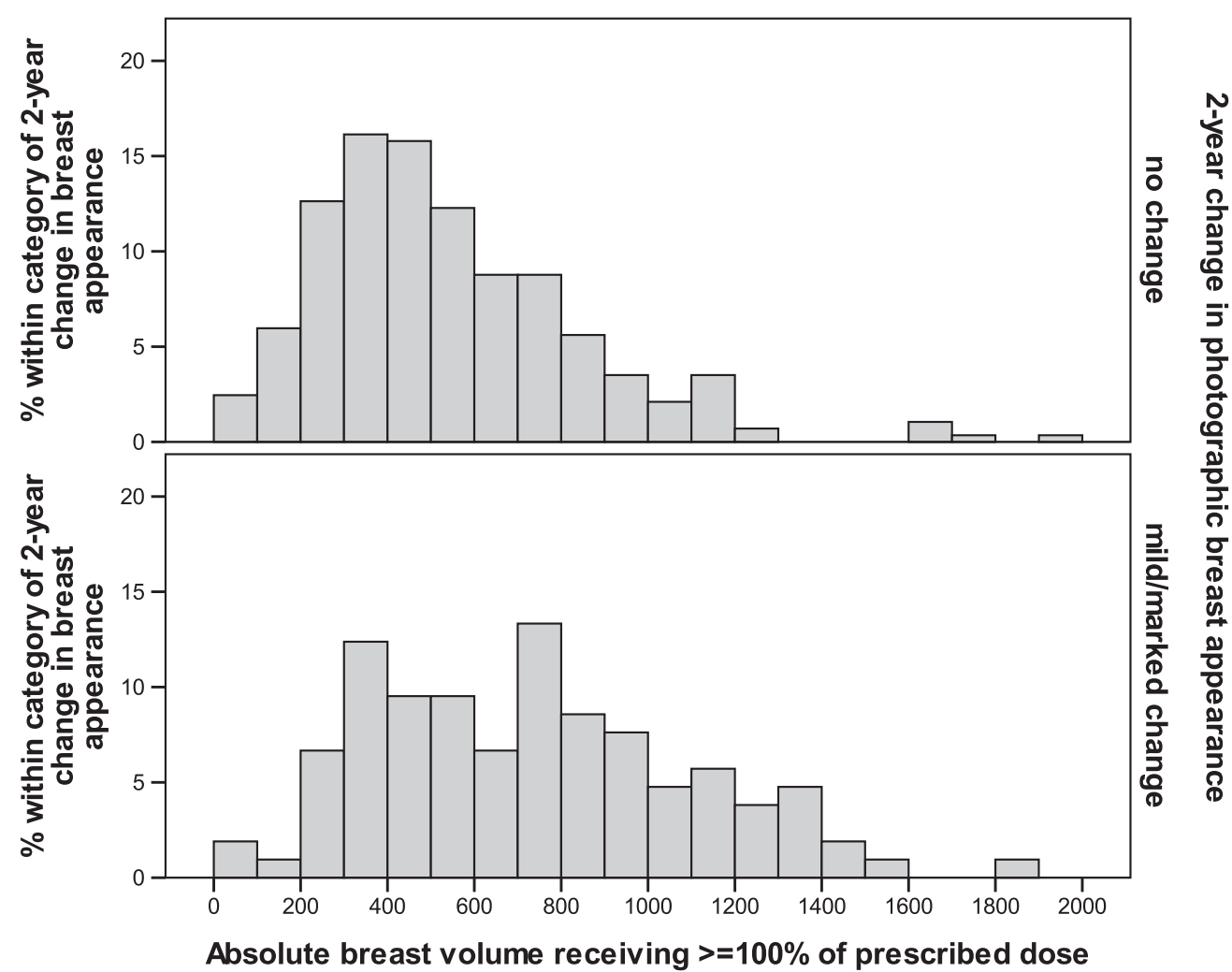

(cc)

Fig. 1. Distribution of absolute breast volume receiving $\geqslant 100 \%$ of prescribed dose in patients with none versus mild/marked change in photographic breast appearance at 2 years.

Table 2

Results of logistic regression analyses testing association between breast volume receiving different levels of prescribed dose (using different definitions of hotspots) and risk of adverse change in 2-year photographic breast appearance, separately for control and hypofractionated treatment schedules.

\begin{tabular}{|c|c|c|c|c|c|}
\hline & \multicolumn{2}{|l|}{ Control schedule } & \multicolumn{3}{|l|}{ Hypofractionated schedules } \\
\hline & $\begin{array}{l}\text { Mild/marked change in breast } \\
\text { appearance at } 2 \text { years/total (\%) }\end{array}$ & $\begin{array}{l}\text { Adjusted } \mathrm{OR}^{\mathrm{b}} \\
(95 \% \mathrm{CI}), p- \\
\text { value }\end{array}$ & $\begin{array}{l}\text { Mild/marked change in breast } \\
\text { appearance at } 2 \text { years/total (\%) }\end{array}$ & $\begin{array}{l}\text { Adjusted } \mathrm{OR}^{2} \\
(95 \% \mathrm{CI}), p- \\
\text { value }\end{array}$ & $\begin{array}{l}\text { Test for heterogeneity between } \\
\text { treatment schedules, } p \text {-value }\end{array}$ \\
\hline $\begin{array}{l}\text { Breast volume receiving } \\
\quad \geqslant 100 \% \text { dose, } \mathrm{cc}^{1}\end{array}$ & & $p=0.17$ & & $p=0.09$ & $p=0.63$ \\
\hline$<529$ & $6 / 60(10.0)$ & 1 & 29/135 (19.1) & 1 & \\
\hline$\geqslant 529$ & $19 / 71(26.8)$ & $\begin{array}{l}2.19(0.71- \\
6.78)\end{array}$ & $51 / 124(41.1)$ & $\begin{array}{l}1.70(0.93- \\
3.13)\end{array}$ & \\
\hline $\begin{array}{l}\text { Breast volume } \\
\quad \text { receiving } \geqslant 103 \% \\
\text { dose,cc }^{1}\end{array}$ & & $p=0.42$ & & $p=0.86$ & $p=0.39$ \\
\hline$<112$ & $8 / 62(12.9)$ & 1 & $35 / 133(26.3)$ & 1 & \\
\hline$\geqslant 112$ & $17 / 69(24.6)$ & $\begin{array}{l}1.52(0.55- \\
4.21)\end{array}$ & $45 / 126(35.7)$ & $\begin{array}{l}0.95(0.52- \\
1.72)\end{array}$ & \\
\hline $\begin{array}{l}\text { Breast volume receiving } \\
\geqslant 105 \% \text { dose, } \mathrm{cc}^{1}\end{array}$ & & $p=0.07$ & & $p=0.29$ & $p=0.29$ \\
\hline$<12$ & $8 / 69(11.6)$ & 1 & $32 / 130(24.6)$ & 1 & \\
\hline$\geqslant 12$ & $17 / 62(27.4)$ & $\begin{array}{l}2.56(0.93- \\
7.02)\end{array}$ & $48 / 129(37.2)$ & $\begin{array}{l}1.36(0.77- \\
2.41)\end{array}$ & \\
\hline $\begin{array}{l}\text { Any breast volume } \\
\text { receiving } \geqslant 107 \% \\
\text { dose? }\end{array}$ & & $p=0.92$ & & $p=0.63$ & $p=0.91$ \\
\hline No & $16 / 88(18.2)$ & 1 & $48 / 164(29.3)$ & 1 & \\
\hline Yes & $9 / 43(20.9)$ & $\begin{array}{l}1.05(0.40- \\
2.80)\end{array}$ & $32 / 95(33.7)$ & $\begin{array}{l}1.15(0.65- \\
2.02)\end{array}$ & \\
\hline
\end{tabular}

$\mathrm{OR}=$ odds ratio.

$\mathrm{CI}=$ confidence interval.

a Medians used to define categories.

b Adjusted for breast size and surgical deficit. 
absolute breast volumes receiving $\geqslant 107 \%$ of prescribed dose were very small, a variable indicating whether or not any volume received $\geqslant 107 \%$ dose was used for the analysis instead.

Due to small numbers of patients with change in breast appearance in some categories, the two hypofractionated schedules were grouped together for the analysis and comparisons were made between the control group (50 Gy in 25 fractions) and a combined hypofractionated treatment group (30 Gy in five fractions and $28.5 \mathrm{~Gy}$ in five fractions). Multiple logistic regression was used to test the association between breast volume receiving different levels of prescribed dose and risk of adverse change in 2-year photographic breast appearance, separately for control and hypofractionated treatment schedules, and adjusting for breast size and surgical deficit (each assessed by a team of three observers as small, medium or large from baseline photographs taken post-surgery but pre-radiotherapy) as these were significant risk factors for adverse effects in this dataset. Finally, the test of heterogeneity was used to compare the effect of dose heterogeneity on changes in breast appearance between the two treatment schedules by fitting an interaction between dose heterogeneity and treatment in the multiple logistic regression model.

\section{Results}

Nine hundred and fifteen patients were recruited from 18 UK radiotherapy centres into the FAST trial between 2004 and 2007. Treatment plans were available in DICOMRT or RTOG electronic formats with full CT planning for 469 patients (51.2\% of 915) from 11 centres, and of these, 390 ( $83.1 \%$ of 469 ) had a score for change in photographic breast appearance at 2 years available, forming the dataset for analysis in this study. Reasons for the 2-year photographic score being unavailable were breast reconstruction (1), recurrence or second primary (3), died (4), emigrated or moved (3), no baseline photograph (17), patient not seen at 2 years (6), 2-year photograph not taken (3), patient withdrew from photographic study (4) and reason unknown (38).

There was no significant difference between the control and hypofractionated treatment groups in terms of median breast volumes receiving $\geqslant 50 \%$ isodose ( $1496 \mathrm{cc}$ for control and $1386 \mathrm{cc}$ for hypofractionated, $p=0.56>0.05$ ). Table 1 summarises the patient tumour and treatment characteristics of the study sample, showing them to be representative of the FAST trial population as a whole $(n=915)$. Age, time between surgery and randomisation, histological type, pathological tumour size, and tumour grade were comparable between the sample and the total FAST population.

At 2 years post-randomisation, 285 (73.1\%) women had no change in photographic breast appearance, $81(20.8 \%)$ had mild change and $24(6.2 \%)$ had marked change. The median breast volume (IQR) for each isodose group $\geqslant 100 \%, \geqslant 103 \%, \geqslant 105 \%$ and $\geqslant 107 \%$ were $529 \mathrm{cc}(335-783), 112 \mathrm{cc}(57-210), 12 \mathrm{cc}(3-31)$ and $0 \mathrm{cc}(0-0.1)$ respectively. One hundred and thirty eight out of 390 patients $(35.4 \%)$ had a volume receiving more than $107 \%$ of the prescribed dose, although the absolute volumes were very small. Fig. 1 shows the overlap between the distributions of breast volumes receiving $\geqslant 100 \%$ of the dose for patients who had none versus any change in photographic breast appearance at 2 years.

Results from the multiple logistic regression analyses are shown in Table 2, and suggested that after adjusting for breast size and surgical deficit, there was no evidence that the risk of late adverse effects of radiotherapy was associated with dose inhomogeneity according to the various definitions of hotspots analysed. As shown by the results of the tests for heterogeneity and the overlapping 95\% confidence intervals for the odds ratios, the effect of residual dose inhomogeneity of whole breast treatment with 3D dose compensations on adverse effects did not vary significantly between the control and hypofractionated schedules, for any of the dosimetry parameters ( $p>0.05$ for all heterogeneity tests).

\section{Discussion}

This study aimed to investigate the impact of dose inhomogeneity on late adverse effects when hypofractionated schedules are introduced, since partial volumes absorbing $>100 \%$ of prescribed dose suffer an increase in both total dose and dose per fraction, so-called double trouble [18]. Based on the linear-quadratic (LQ) formulation, hot spots are penalised more severely in a hypofractionated treatment, the so-called treble trouble effect $[18,19]$. In theory, the clinical effect is expected to be very small, but there is a lingering concern that it might matter in practice, especially if dosimetry is suboptimal. Due to the size and shape of the target volume encompassed in whole breast radiotherapy, there is greater dose heterogeneity than other tumour sites, with up to $28 \%$ dose heterogeneity using conventional 2-dimensional planning [20]. Recent ASTRO guidelines for hypofractionated whole breast radiotherapy recommend the use of three-dimensional dose compensation to optimise dose homogeneity when breast hypofractionation is used, although this measure is beneficial with conventional fractionation too [21]. Five fractions of $5.7 \mathrm{~Gy}$, as tested in the FAST trial for example, are iso-effective with $50 \mathrm{~Gy}$ in 25 fractions at the $100 \%$ reference point, assuming $\alpha / \beta=3 \mathrm{~Gy}$ [12]. Partial volumes receiving $105 \%$ of this prescribed dose absorb an equivalent total dose expressed in $2.0 \mathrm{~Gy}$ fractions of $54.3 \mathrm{~Gy}$ after five fractions of $5.7 \mathrm{~Gy}$ compared to $53.5 \mathrm{~Gy}$ after 25 fractions of $2.0 \mathrm{~Gy}$. This dose difference encompassing the whole breast would be clinically significant, but delivered to partial volumes comprising a few percent of whole breast are not relevant. In the present study, all participating centres achieved the requirement, as indicated by median (IQR) volumes of $105 \%$ and $107 \%$ hotspots of $12 \mathrm{cc}(3-31)$ and $0 \mathrm{cc}(0-0.1)$, respectively. The study detected no excess risk of adverse effects attributable to hotspots in the hypofractionated treatment schedules (5.7 or $6.0 \mathrm{~Gy}$ per fraction) compared with hotspots in the conventional $2 \mathrm{~Gy}$ treatment schedule. In other words, there was no evidence for a treble trouble effect in the FAST patient dataset.

Only $40 \%$ of the FAST trial sample population were used in this analysis due to limitations in the central collection of 3D dosimetry datasets, but there is no evidence to suggest that the patients included in this study are unrepresentative the FAST trial population. Change in photographic breast appearance at 2 years was used to define the late adverse effect caused by radiotherapy in this study. This endpoint has been well established and validated in randomised clinical trials, indicating it to be sensitive to small $(<10 \%)$ differences in randomised total dose [1-3,7,11]. The 2-year timepoint is predictive of the relative effects of randomised groups at longer follow up, even though the absolute rate of adverse effects continues to rise for at least a decade and probably for life $[7,22,23]$. The limiting factor is not, therefore, the 2-year timepoint, but the total number of adverse events available for analysis, and particularly when stratified by treatment schedule. Although the statistical power to adequately test formally for heterogeneity is low, based on 105 adverse events recorded in 390 patients, the $95 \%$ confidence intervals on the odds ratios for hypofractionated treatments according to size of partial volumes receiving $>100 \%$ prescribed dose are narrow enough to reassure.

\section{Conclusion}

Assuming ICRU limits on dosimetry can be met, there is no evidence that the adoption of hypofractionation enhances the adverse impact of residual dose inhomogeneity on the risk of late adverse 
effects of radiation recorded by change in photographic breast appearance.

\section{FAST Trial Management Group}

Rajiv K. Agrawal (Shrewsbury Hospital); Abdulla Alhasso (Beatson Cancer Centre); Peter J. Barrett-Lee (Velindre Hospital, Cardiff); Judith M. Bliss (ICR-CTSU, Institute of Cancer Research); Peter Bliss (Torbay Hospital); David Bloomfield (Royal Sussex County Hospital); Joanna Bowen (Cheltenham General Hospital); A Murray Brunt (University Hospital of North Staffordshire); Ellen Donovan (Royal Marsden NHS Foundation Trust, Sutton); Marie Emson (ICR-CTSU, Institute of Cancer Research); Andrew Goodman (Royal Devon \& Exeter Hospital); Adrian Harnett (Norfolk and Norwich University Hospital); Joanne S. Haviland (ICR-CTSU, Institute of Cancer Research); Ronald Kaggwa (ICR-CTSU, Institute of Cancer Research); James P. Morden (ICR-CTSU, Institute of Cancer Research); Anne Robinson (Southend Hospital); Sandra Simmons (ICR-CTSU, Institute of Cancer Research); Alan Stewart (Christie Hospital); Mark A. Sydenham (ICR-CTSU, Institute of Cancer Research); Isabel Syndikus (Clatterbridge Centre for Oncology); Jean Tremlett (Royal Sussex County Hospital); Yat Tsang (Mount Vernon Hospital); Duncan Wheatley (Royal Cornwall Hospital); Karen Venables (Mount Vernon Hospital); John R Yarnold (Institute of Cancer Research, Royal Marsden NHS Foundation Trust Sutton).

\section{Principal investigators according to radiotherapy centre}

Beatson Oncology Centre, Glasgow, A. Alhasso; Cheltenham General Hospital, Cheltenham, P. Jenkins; Christie Hospital, Manchester, A. Stewart; Clatterbridge Centre for Oncology, Bebington, I. Syndikus; Ipswich Hospital, Ipswich, E. Sherwin; Leeds General Hospital, Leeds, S. Kumar; Norfolk and Norwich University Hospital, Norwich, A. Harnett; Queens Hospital, Romford, M. Quigley; Royal Cornwall Hospital, Treliske, D. Wheatley; Royal Devon and Exeter Hospital, Exeter, A. Goodman; Royal Marsden Hospital, Sutton, J.R. Yarnold; Royal Preston Hospital, M Hogg; Royal Shrewsbury Hospital, Shrewsbury, R.K. Agrawal; Royal Sussex County Hospital, Brighton, D. Bloomfield; Southend General Hospital, Southend, A. Robinson; Torbay District General Hospital, Torbay, P. Bliss; University Hospital of North Staffordshire, Stoke-on-Trent, A.M. Brunt; Velindre Hospital, Cardiff, P.J. Barrett-Lee.

\section{Conflict of interest statement}

The authors declare no conflict of interest.

\section{Acknowledgements}

We thank all the patients who participated in this study, and the doctors, nurses, radiographers, physicists, and data managers at the participating centres. We acknowledge the support of The Royal College of Radiologists (UK). We acknowledge NHS funding to the NIHR Biomedical Research Centre. We thank Cancer Research UK who provides the core Grant for ICR-CTSU (Grant C1491/A9895). The Cancer Research UK number for the FAST Trial is CRUKE/04/015.
Y. Tsang and K. Venables are supported by a Grant to the National Radiotherapy Quality Assurance team from the National Institute of Health Research.

\section{References}

[1] Bentzen SM, Agrawal RK, Aird EG, Barrett JM, Barrett-Lee PJ, Bliss JM, et al. The UK Standardisation of Breast Radiotherapy (START) Trial A of radiotherapy hypofractionation for treatment of early breast cancer: a randomised trial. Lancet Oncol 2008;9:331-41.

[2] Bentzen SM, Agrawal RK, Aird EG, Barrett JM, Barrett-Lee PJ, Bliss JM, et al. The UK Standardisation of Breast Radiotherapy (START) Trial B of radiotherapy hypofractionation for treatment of early breast cancer: a randomised trial. Lancet 2008;371:1098-107.

[3] Owen JR, Ashton A, Bliss JM, et al. Effect of radiotherapy fraction size on tumour control in patients with early-stage breast cancer after local tumour excision: long-term results of a randomised trial. Lancet Oncol 2006;7:467-71.

[4] Whelan T, MacKenzie R, Julian J, et al. Randomized trial of breast irradiation schedules after lumpectomy for women with lymph node-negative breast cancer. J Natl Cancer Inst 2002;94:1143-50.

[5] Whelan TJ, Pignol JP, Julian J, et al. Long-term results of a randomized trial of accelerated hypofractionated whole breast irradiation following breast conserving surgery in women with node-negative breast cancer. Int J Radiat Oncol Biol Phys 2008;72:A60, S28.

[6] Whelan TJ, Pignol JP, Levine MN, et al. Long-term results of hypofractionated radiation therapy for breast cancer. N Engl J Med 2010;362:513-20.

[7] Yarnold J, Ashton A, Bliss J, et al. Fractionation sensitivity and dose response of late adverse effects in the breast after radiotherapy for early breast cancer: long-term results of a randomized trial. Radiother Oncol 2005;75:9-17.

[8] Bartelink H, Arriagada R. Hypofractionation in radiotherapy for breast cancer. Lancet 2008;371:1050-2.

[9] Glatstein E. Hypofractionation, long-term effects, and the alpha/beta ratio. Int J Radiat Oncol Biol Phys 2008;72:11-2.

[10] Yarnold J, Bentzen SM, Coles C, Haviland J. Hypofractioned whole breast radiotherapy for women with early breast cancer: myths and realities. Int J Radiat Oncol Biol Phys 2011;79:1-9.

[11] Donovan E, Bleakley N, Denholm E, Evans P, Gothard L, Hanson J, et al. Breast Technology Group. Randomised trial of standard 2D radiotherapy (RT) versus intensity modulated radiotherapy (IMRT) in patients prescribed breast radiotherapy. Radiother Oncol 2007;82:254-64.

[12] FAST Trialists group. First results of the randomised UK FAST Trial of radiotherapy hypofractionation for treatment of early breast cancer (CRUKE) 04/015). Radiother Oncol 2011;100:93-100.

[13] International Commission on Radiation Units and Measurements (ICRU). ICRU report 50: prescribing, recording, and reporting photon beam therapy. Bethesda, USA: International Commission on Radiation Units And Measurements (ICRU); 1999.

[14] International Commission on Radiation Units and Measurements (ICRU). ICRU Report 62: prescribing, recording and reporting photon beam therapy (supplement to ICRU report 50). Bethesda, USA: International Commission On Radiation Units And Measurements (ICRU); 1999.

[15] Haviland J, Ashton A, Broad B, et al. Evaluation of a method for grading late photographic change in breast appearance after radiotherapy for early breast cancer. Clin Oncol 2008;20:497-501.

[16] START-Standardisation of Breast Radiotherapy, trial protocol; 1998.

[17] Goldsmith C, Haviland J, Tsang Y, Sydenham M, Yarnold J. Large breast size as a risk factor for late adverse effects of breast radiotherapy: is residual dose inhomogeneity, despite 3D treatment planning and delivery, the main explanation? Radiother Oncol 2011;100:236-40.

[18] Jones B, Dale RG, Finst P, et al. Biological equivalent dose assessment of the consequences of hypofractionated radiotherapy. Int J Radiat Oncol Biol Phys 2000;47:1379-84.

[19] Fowler J. The linear quadratic formula and progress in fractionated radiotherapy. Br J Radiol 1989;62:679-94.

[20] Neal AJ, Torr M, Helyer S, Yarnold JR. Correlation of breast dose heterogeneity with breast size using 3D CT planning and dose-volume histograms. Radiother Oncol 1995;34:210-8.

[21] Smith BD, Bentzen SM, Correa CR, et al. Fractionation on whole breast irradiation: an American Society for Radiation Oncology (ASTRO) evidencebased guideline. Int J Radiat Oncol Biol Phys 2011;81:59-68.

[22] Barnett GC, Wilkinson JS, Moody AM, et al. Randomized controlled trial of forward-planned intensity-modulated radiotherapy for early breast cancer: interim results at 2 years. Int J Radiat Oncol Biol Phys 2012;82:715-23.

[23] Turesson I, Nyman J, Holmberg E, et al. Prognostic factors for acute and late skin reactions in radiotherapy patients. Int J Radiat Oncol Biol Phys 1996;36:1065-75 